\title{
The Knee Joint Tissues Differ Significantly in TGFß1 Expression and Its Sensitivity
}

\author{
Sadanand Fulzele $^{1 *}$, Monte Hunter ${ }^{1}$, Rajnikumar Sangani ${ }^{1}$, Norman Chutkan ${ }^{1}$, \\ Carlos Isales ${ }^{1}$, Mark W. Hamrick ${ }^{2}$ \\ ${ }^{1}$ Department of Orthopaedic Surgery, Medical College of Georgia, Augusta, USA \\ ${ }^{2}$ Department of Cellular Biology and Anatomy, Medical College of Georgia, Augusta, USA \\ Email: ${ }^{*}$ sfulzele@mail.mcg.edu
}

Received July 17, 2013; revised August 17, 2013; accepted August 24, 2013

Copyright (C) 2013 Sadanand Fulzele et al. This is an open access article distributed under the Creative Commons Attribution License, which permits unrestricted use, distribution, and reproduction in any medium, provided the original work is properly cited.

\begin{abstract}
The knee joint is the largest and most complex joint in the human body. In this study, we investigated TGF $\beta 1$ expression in the outer meniscus, inner meniscus and articular cartilage of rabbit and human knee tissue (outer and inner menisci) in order to determine the potential role of this factor in normal meniscal function. We also examined the potential of TGF- $\beta 1$ stimulation to promote tissue regeneration in the two different regions of rabbit knee meniscus tissue. Immunohistochemical investigations of TGF- $\beta 1$ were performed on rabbit and human knee tissue. The rabbit outer, inner and articular cartilage cells were culture and stimulated with TGF- $\beta 1$ followed by cell proliferation assay and extracellular matrix analysis. Regulatory studies were performed using TGF- $\beta 1$ inhibitors SB-431542 and PD98059. Gene expression was analyzed by quantitative polymerase chain reaction. We found marked regional variation in the expression of TGF- $\beta 1$ in rabbit and human knee. TGF- $\beta 1$ expressions are relatively greater in the outer meniscus than inner meniscus. Furthermore, we found that exogenous TGF- $\beta 1$ stimulation increased cell proliferation and aggrecan synthesis more so in the outer than in the inner meniscus. Articular cartilage tissue shows moderate levels of cell proliferation and ECM synthesis when compared with outer and inner meniscus. These findings suggest that growth factors used to enhance the repair and regeneration of meniscal tissue should be tailored to enhance region-specific variation in cell proliferation and extracellular matrix synthesis.
\end{abstract}

Keywords: Meniscus; Outer Meniscus; Inner Meniscus; TGF $\beta 1$; Articular Cartilage

\section{Introduction}

The knee joint is one of the largest articulations in the body. Menisci within the knee are crucial to its proper function. The meniscus of the knee is functionally a twocomponent connective tissue that distributes compressive load and acts as a lubricated bearing surface for rotation and sliding of the femoral condyles upon the tibial plateau [1]. The two components are the outer and inner menisci, which differ in the predominant collagen and proteoglycan isomers that constitute them. The inner meniscus is an avascular zone that contains primarily type II collagen and higher glycosaminoglycans (GAGs), whereas outer meniscus contains mostly type I and less GAGs [2]. A torn meniscus can result from any activity that causes forcefully twist or rotate knee, such as aggressive pivoting or sudden stops and turns. Torn menisci

\footnotetext{
${ }^{*}$ Corresponding author.
}

causes significant pain and disability and thus, require expeditious management. Failure of the meniscus to withstand the high stresses applied to it results in the common clinical condition of a meniscal tear. Treatment of tears is confounded by a limited blood supply, which effectively ends at the transition of the inner and outer regions [3]. To aid healing of torn menisci, investigators are now examining the potential of growth factor therapy. Primary candidates among these are basic fibroblast growth factor bFGF [4], TGF- $\beta[5,6]$ and platelet derived growth factor-AB. Previous studies have indicated a dramatic, order-of-magnitude effect on meniscal cell proliferation with exogenous $\mathrm{bFGF}$ in monolayer culture [4].

Other than meniscus, articular cartilage is also important tissue of knee. Damaged articular cartilage has a limited regenerative potential and is responsible for considerable disability in the form of arthritis and joint 
trauma. Once articular cartilage substance is lost, the damage is generally permanent and is often progressive [7]. In the normal articular joint, cartilage homeostasis is maintained by a balance between the synthesis and degradation of articular cartilage composed of proteoglycans and type II collagen [8]. However, in Osteoarthritis (OA), the balance shifts toward catabolism, leading to cartilage destruction because of excessive production of proteolytic enzymes. On the other hand, the articular cartilage is hard to regenerate during the development of OA. Several investigator have used Insulin-like growth factor I (IGF-I) [9], fibroblast growth factor-2 (FGF-2) [10] and $\operatorname{TGF} \beta[11]$, the cell-regulatory molecules that promote anabolic and mitogenic activities by articular chondrocytes which may possess therapeutic potential.

The growth factor TGF- $\beta$ is an important factor for cartilage development (chondrogenesis), its maintenance and regeneration [12]. Transforming growth factor- $\beta$ (TGF- $\beta$ ) superfamily, composed of TGF- $\beta$, bone morphogenic protein (BMP), activin and cartilage-derived growth factor (CDGF) subfamilies, regulates a variety of cellular processes including embryonic differentiation, extracellular matrix formation, cell proliferation and apoptosis $[13,14]$. TGF- $\beta$ stimulates chondrocyte differentiation by accumulating chondrocyte-specific gene expression such as type II collagen and aggrecan. In addition, TGF- $\beta$ can potentially inhibit the release of catalytic factors, which are elevated in osteoarthritis [15]. Based on the available evidence obtained from various in vitro and in vivo studies, TGF- $\beta$ is considered a potentially useful agent for the treatment of arthritic conditions.

The aim of this study was to assess the effects of recombinant TGF- $\beta 1$ on the activity of different region of knee tissue particularly articular cartilage and meniscal cells harvested from the inner and outer zones of the meniscus. We hypothesized that there is regional variation in the expression and stimulatory effect of TGF- $\beta 1$ on knee tissue. This is the first report showing the regional variation in expression of TGF- $\beta 1$ in human and rabbit knee tissue as well as differential stimulatory effect of $\mathrm{TGF} \beta 1$ on the different region of the knee tissue in rabbit model. The study was designed to 1) analyze the steady-state level of TGF $\beta 1$ expression and its effect on cell proliferation in different region of knee tissue 2) to determine the TGF $\beta 1$ signaling pathway using transcription inhibitor, and 3) to analysis the effect of TGF $\beta 1$ on knee chondrocytes specific gene expression such as collagen type II and proteoglycan. This study would also enable the investigators to assess whether cells from the avascular regions of the meniscus have the ability to proliferate and produce extracellular matrix (ECM) in a similar manner as cells from the vascular region, when exposed to TGF- $\beta 1$ in vitro.

\section{Material and Method}

\subsection{Primary Cell Culture}

Four month-old New Zealand white rabbits $(n=6)$ were sacrificed and articular Cartilage, Inner and Outer menisci were harvested. The meniscus was divided approximately at the radial midpoint to separate the inner and outer portions. The cells were isolated by 2-hr digestion at $37^{\circ} \mathrm{C}$ in $0.05 \%$ pronase (Roche Diagnostics, Indianapolis) followed by overnight digestion at $37^{\circ} \mathrm{C}$ in $0.2 \%$ collagenase (type II, Worthington Biochemical, Lakewood, NJ) using F12 medium (Mediatech, Herndon, VA) modified with $4.8 \mathrm{mM} \mathrm{CaCl}_{2}$ (Sigma, St. Louis, MO) and $40 \mathrm{mM}$ HEPES buffer (Sigma). The cells were washed in phosphate buffered saline (PBS, Fisher Biotech, Fair Lawn, NJ) and plated at $2.0 \times 10^{4} \mathrm{cells} / \mathrm{cm}^{2}$ in 100-mm tissue culture plates (Becton Dickinson Labware, Franklin Lakes, NJ), then grown for 10 days with $3 \times$ /week changes of supplemented Hams F12 medium (Mediatech) containing $50 \mathrm{U} / \mathrm{ml}$ penicillin, $50 \mathrm{ug} / \mathrm{ml}$ streptomycin (Mediatech), 1\% l-glutamine (Hyclone), and $10 \%$ fetal bovine serum (FBS, Hyclone). Cells were treated with $0.25 \%$ trypsin (Mediatech) for 5 minutes on a rotating table to ease detachment when plating the test samples.

\subsection{Human Patients' Samples}

Meniscus tissues from patients $(\mathrm{n}=5)$ were acquired after joint replacement surgeries. We obtained informed consent from each patient. The experimental protocol was approved by the Institutional Review Board. The outer and inner meniscus were separated and used for immunohistochemistry. The tissue were embedded in OCT, snap frozen in liquid nitrogen, and cryostatin sections cut at $6-8$ um for immunohistochemistry.

\subsection{Chondrocytes Culture and Treatment with TGF- $\beta 1$ and Its Inhibitors}

Fibroblasts were passage upon reaching 70\% confluence. After the last passage, fibroblasts were expanded until reaching $70 \%$ confluence on 12 well culture plates for RNA and 96 well plates for cell proliferation and inhibitory study. Chondrocytes fibroblasts were then starved of serum for $24 \mathrm{~h}$ before treatment by replacing serum containing media with DMEM plus $1 \%$ Antibiotic plus $1 \times$ insulin-transferrin-selenium supplement (Invitrogen). Recombinant TGF- $\beta 1$ (R \& D Systems) was dissolved into the serum-free media at a final concentration of 5 or $10 \mathrm{ng} / \mathrm{ml}$. Stock solutions of inhibits TGF- $\beta$ RI activity (SB-431542) and inhibitor of MEK1/2 activation (PD98059) were prepared by dissolving these solid anhydrous compounds in dimethyl sulfoxide (DMSO). These stock solutions were then added to serum-free media containing at 
a final concentration of $20 \mu \mathrm{m}$ for SB-431542 and $30 \mu \mathrm{m}$ concentration of PD98059. Fibroblasts were pretreated with SB-431542 and PD98059 for $1 \mathrm{~h}$ before treatment with TGF- $\beta 1$.

\subsection{Proliferation Assays}

The number of viable cultured cells in proliferation was determined using a Promega CellTiter $96^{\circledR}$ AQueous One MTS Cell Proliferation Assay. Briefly, cells were plated in triplicate at an initial density of $5000 / \mathrm{cm}^{2}$ in 96 -well plates (BD Labware) using supplemented Hams F12 medium containing 5\% FBS to support overnight attachment. The following day, fibroblasts were starved of serum for $24 \mathrm{~h}$ before treatment by replacing serum containing media with Ham F12 media plus containing 50 $\mathrm{U} / \mathrm{ml}$ penicillin, $50 \mathrm{ug} / \mathrm{ml}$ streptomycin plus $1 \times$ ITS (Insulin Transferrin Selenium supplement (BD Biosciences, Bedford, MA). The next day cells were fed with fresh supplemented Hams F12, substituting the FBS with $1 \%$ ITS and adding 5 and $10 \mathrm{ng} / \mathrm{ml}$ of recombinant TGF- $\beta 1$ for $24 \mathrm{hr}, 48 \mathrm{hrs}$ and $72 \mathrm{hrs}$. Cells were washed with PBS twice and add $100 \mu \mathrm{l}$ of Media and $20 \mu \mathrm{l}$ of MTS (CellTiter $96^{\circledR}$ AQueous One Solution Reagent, Promega) assay buffer for $3 \mathrm{hr}$ and incubate at $37^{\circ} \mathrm{C}$ in a humidified, $5 \% \mathrm{CO}_{2}$ incubator. Optical density (OD) was read at 490 $\eta \mathrm{m}$.

\section{5. mRNA Determination by Real-Time Polymerase Chain Reaction}

After 16 hrs of TGFbl stimulation, ribonucleic acid (RNA) was extracted by TRIzol ${ }^{\circledR}$ (Invitrogen), following manufacturer's instructions, and assayed for absorbance at 260 and $280 \mathrm{~nm}$ (Helios-Gamma, Thermo Spectronic, Rochester, NY). The RNA was reverse-transcribed into complementary deoxyribonucleic acid (cDNA) using iScript reagents from Bio-Rad on a programmable thermal cycler (PCR-Sprint, Thermo Electron, Milford, MA). $50 \mathrm{ng}$ of cDNA was amplified in each real-time polymerase chain reaction using a Bio-Radi Cycler, ABgene reagents (Fisher scientific) and custom-designed primers for the ECM genes specific (Table 1) to the rabbit. An glyceraldehyde-3-phosphate dehydrogenase (GAPDH) threshold cycles was used to normalize the expression of the target genes to the constitutive transcriptional activity.

\subsection{Immunohistochemistry}

Articular cartilage and portions of the outer and inner meniscus were embedded in OCT, snap frozen in liquid nitrogen, and cryostat in sections cut at $6-8 \mathrm{um}$. Sections were fixed with cold acetone for 5 minutes, blocked in normal donkey serum, and incubated with primary TGF $\beta 1$ antibody (Santa Cruz, Inc.) for $2 \mathrm{hrs}$ at room temperature then washed and incubated with FITC-labeled goat anti-mouse secondary antibody. Sections were counterstained with DAPI and mounted using aqueous medium.

\subsection{Statistical Analysis}

Data are expressed as the mean SD. Differences in measured variables between experimental and control groups were assessed using Student's t-test. A p-value < 0.05 was considered statistically significant in between sample comparisons.

\section{Results}

\subsection{Differential Expression of TGF $\beta$ in Rabbit and Human Knee Tissue}

The immunostaining results show that TGF- $\beta$ is present in all different type of rabbit knee tissue. Outer meniscus shows the most abundant amount of TGF- $\beta$ and inner meniscus the least in rabbit knee tissue (Figure 1(a)). The rabbit articular cartilage showed the moderate level of TGF- $\beta$ (Figure 1(a)). Human knee tissue also showed similar type of results as rabbit knee tissue. Outer meniscus showed most expression of TGF- $\beta 1$ than inner meniscus (Figure 1(b)).

\subsection{Effect of TGF- $\beta 1$ on Knee Chondrocytes Proliferation}

The rabbit meniscus and articular cartilage cells were grown on 96 well cell culture plates and stimulate with and without TGF- $\beta 1$. The morphology of cells exposure

Table 1. Nucleotide sequences of rabbit gene primers used for real time-PCR.

\begin{tabular}{|c|c|c|c|c|}
\hline Gene & Primer Sequence & Product size in base pair & Annealing temperature $\left({ }^{\circ} \mathrm{C}\right)$ & Reference \\
\hline GAPDH & $\begin{array}{c}\text { 5'GTC GTC TCC TGC GAC TTC AAC 3' } \\
\text { 5'TAC CAG GAA ATG AGC TTC ACA AAG 3' }\end{array}$ & 100 & 60 & L23961 \\
\hline COL-2 & $\begin{array}{l}\text { 5'GCT CTG AAC AGC CAA AGG AC 3' } \\
\text { 5'TCT GCC CAG TTC AGG TCT CT 3' }\end{array}$ & 191 & 60 & S83370 \\
\hline Aggrecan & $\begin{array}{l}\text { 5'CTG GGT GTC AGG ACC GTG TA 3' } \\
\text { 5'TTC GCC TGT GTA GCA GAT GG 3' }\end{array}$ & 90 & 60 & L38480 \\
\hline Biglycan & $\begin{array}{l}\text { 5'CCT CCA GGT GGT CTA TCT GC 3', } \\
\text { 5'GAG GCT GAT GCC GTT GTA GT 3' }\end{array}$ & 75 & 60 & AF020290 \\
\hline
\end{tabular}




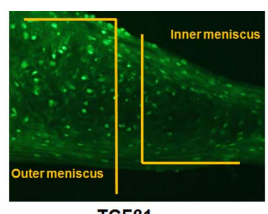

TGFß1

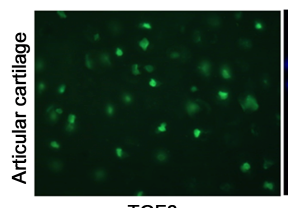

TGF $\beta$
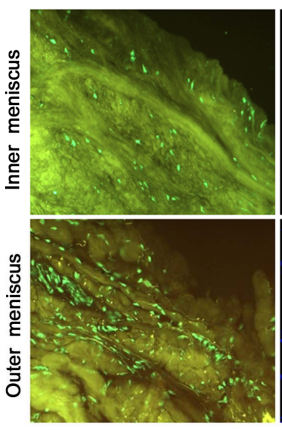

TGFß1
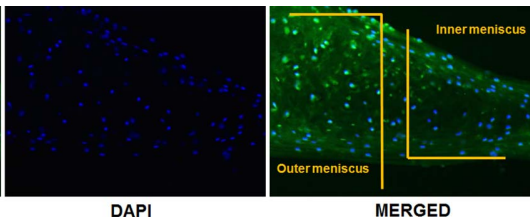

MERGED

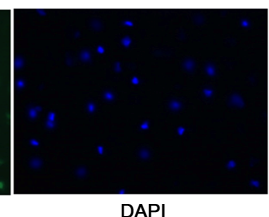

(a)

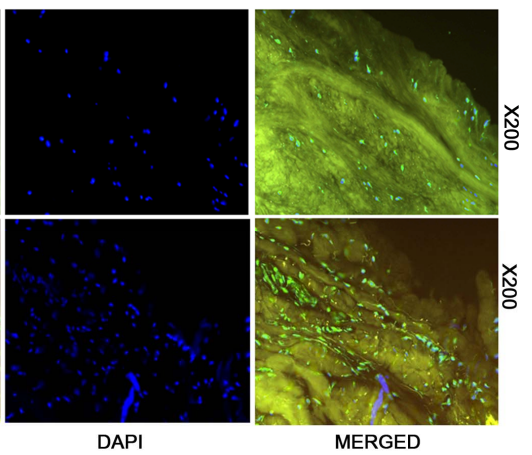

(b)

Figure 1. Immunofluorescent staining of (a) inner meniscus, outer meniscus, and articular cartilage tissue using TGF- $\beta 1$ antibodies for rabbit knee tissue; (b) Immunofluorescent staining of inner and outer meniscus tissue using antibodies specific for human TGF $\beta 1$.

to TGF- $\beta 1$ showed no striking difference compared with the control group. MTT proliferation assay showed that TGF- $\beta 1$ significantly stimulated the proliferation of all different type of chondrocytes in a dose-dependent manner (Figure 2). We found that $10 \eta \mathrm{g} / \mathrm{ml}$ concentrations stimulate more cell proliferation than $5 \mathrm{ng} / \mathrm{ml}$ TGF- $\beta 1$ (Figure 3). So we carried out all experiment with concentration with $10 \mathrm{ng} / \mathrm{ml}$ concentration unless it mention. To determine whether TGF- $\beta 1$ induced the proliferation of chondrocytes, chondrocytes were cultured on 96 well plates and subsequently treated with TGF- $\beta 1$ for 24,48 and $72 \mathrm{hrs}$.

TGF- $\beta 1$ treatment with concentration of $10 \mathrm{ng} / \mathrm{ml}$ increased chondrocytes cell proliferation in outer, inner and articular cartilage cell. Outer meniscus showed more cell proliferation than inner meniscus whereas articular cartilage showed moderate level of cell proliferation.

\subsection{Influence of Pathway Inhibitors Blocked Cell Growth under TGF- $\beta 1$ Stimulation}

MEK1/2 are critical members of the MAPK pathway that have been shown to be involved in the growth and cell proliferation of cells. PD98059 is a potent and specific

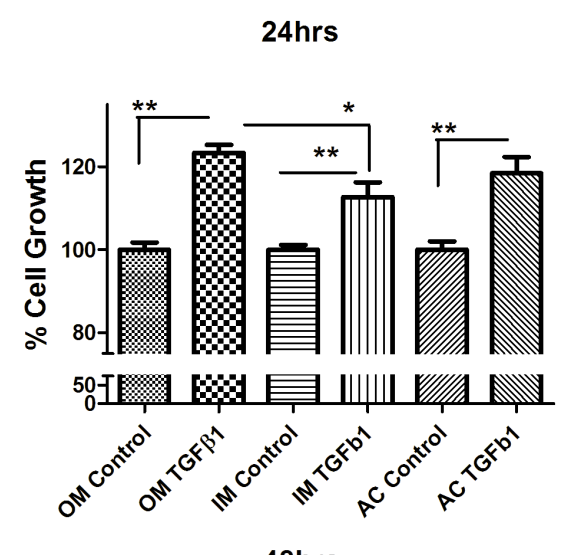

48hrs

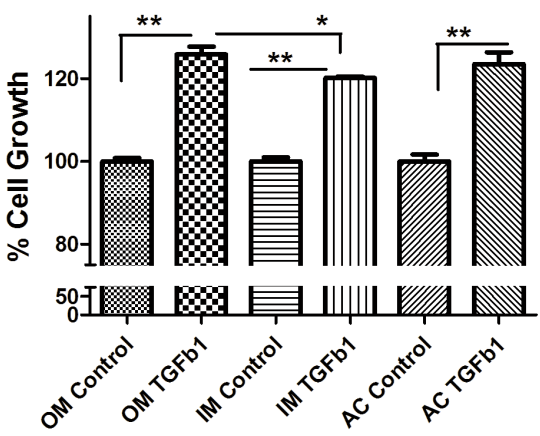

72hrs

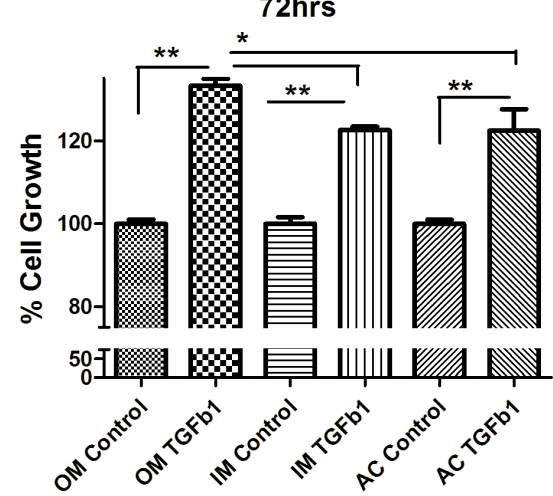

Figure 2. MTT proliferation assay of (a) outer (OM), (b) inner (IM) and (c) articular cartilage (AC) chondrocytes treated with concentrations $(10 \mathrm{ng} / \mathrm{ml})$ of recombinant TGF- $\beta 1$. Data were recorded 24,48 , and 72 hours following treatment $(n=4)$. Data were analyzed by ANOVA followed by Bonferroni post hoc test $\left({ }^{*} \mathrm{p}<0.05 ;{ }^{* *} \mathrm{p}<0.01\right)$.

cell-permeable inhibitor of MEK1/2 activation. As shown in figure (Figure 3), $10 \mathrm{ng} / \mathrm{ml}$ TGF- $\beta 1$ treatment increased cell proliferation in all different types of chondrocytes. Pretreatment with the $30 \mu \mathrm{m}$ concentration of PD98059 for one hour prior to TGF- $\beta 1$ treatment, an inhibitor of extracellular signal regulated kinase (ERK1/2) significantly decrease the cell proliferation by $90 \%$ for outer, inner and AC cells when compared to with the TGF- $\beta$ 1-treated group (Figure 3).

SB-431542 is a novel small molecule that potently in 


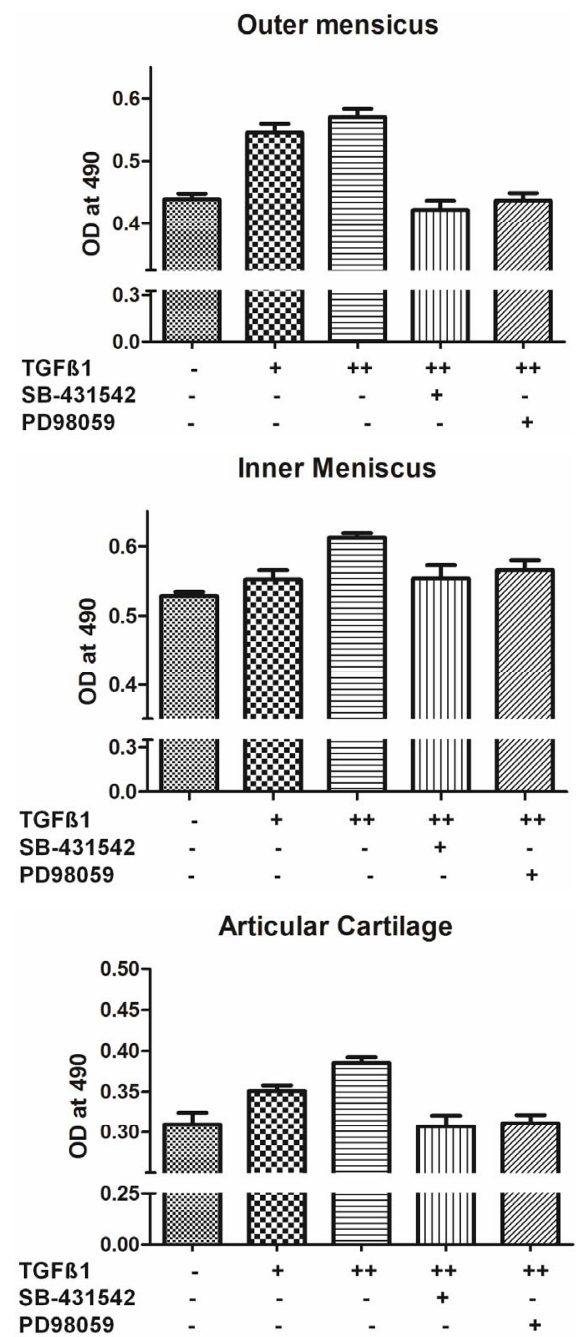

Figure 3. TGF- $\beta 1$ inhibitors inhibit cell proliferation. MTT assay of inner, outer and articular cartilage chondrocytes treated with concentrations ${ }^{+} 5 \mathrm{ng} / \mathrm{ml}$ TGF- $\beta 1,{ }^{++} 10 \mathrm{ng} / \mathrm{ml}$ TGF- $\beta 1,{ }^{*} 20$ uM SB-431542 and ${ }^{\#}$ PD98059 30 uM (n = 4).

hibits TGF- $\beta$ type I receptor activity $[16,17]$. The cells pretreated with $20 \mu \mathrm{m}$ SB-431542 and followed by 10 $\mathrm{ng} / \mathrm{ml}$ TGF- $\beta 1$ treatment showed significant decrease in cell proliferation by $90 \%-100 \%$ in outer, Inner and AC cells compared to TGF- $\beta 1$ treated group (Figure 3). Taken together, these results suggest that $30 \mu \mathrm{m}$ concentration of PD98059 and $20 \mu \mathrm{m}$ SB-431542 can effectively inhibit TGF- $\beta 1$ signal transduction mediated growth.

\subsection{TGF- $\beta 1$ Induces the Expression of Type II Collagen and Proteoglycan in Chondrocytes}

The next step was to determine whether TGF- $\beta 1$ regulated the expression of collagen type II and proteoglycan like aggrecan and biglycan. We measure the mRNA level of Collagen type II, aggrecan and biglycan in outer, inner and $\mathrm{AC}$ chondrocytes after $24 \mathrm{hrs}$ of $10 \mathrm{ng} / \mathrm{ml}$ TGF- $\beta 1$ treatment. TGF- $\beta 1$ stimulated type II collagen synthesis in outer, inner and $\mathrm{AC}$ chondrocytes but most up-regulation in inner meniscus than outer and articular cartilage. The mRNA level of aggrecan and biglycan was also upregulatedin outer, inner and $\mathrm{AC}$ chondrocytes after treatment of TGF- $\beta 1$. Outer meniscus showed most aggrecan up-regulation whereas inner meniscus showed biglycan compare to others (Figure 4).

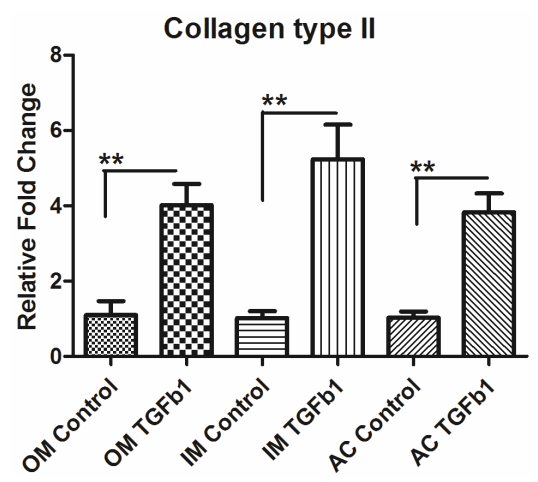

Aggrecan

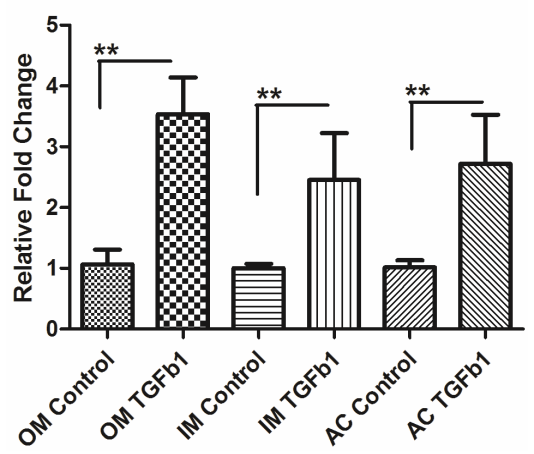

Biglycan

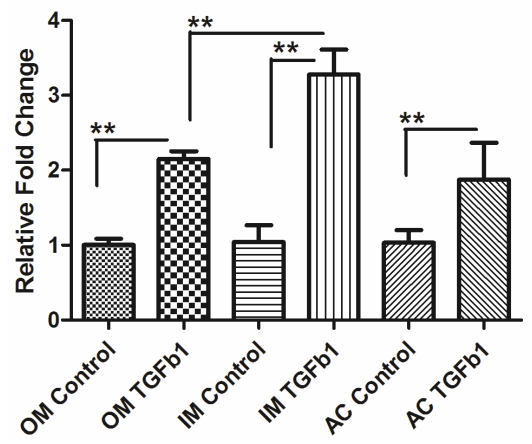

Figure 4. Real-time PCR analysis of (a) type II collagen, (b) Aggrecan, and (c) Biglycan expression in inner (IM), outer (OM) and articular cartilage (AC) chondrocytes treated with $10 \mathrm{ng} / \mathrm{ml}$ concentrations of recombinant TGF- $\beta 1$. Data were recorded after 16 hrs hours following treatment. Data for each sample were normalized with glyceraldehyde-3phosphate dehydrogenase (GAPDH) mRNA. Data (means \pm $\mathrm{SD}, \mathrm{n}=6$ ) are represented as the fold change in expression compared to control. " $P<0.05$. Data were analyzed by ANOVA followed by Bonferroni post hoc test ( ${ }^{*} \mathrm{p}<0.05$; ${ }^{* * *} \mathrm{p}$ $<0.01$ ). 


\section{Discussion}

Although TGF- $\beta 1$ is a potent inhibitor of growth in most cell types, it has been shown to stimulate growth of certain cells in culture, such as mouse bone marrow mesenchymal stem cells [18], rat and avian articular chondrocytes $[19,20]$, human nasal septal chondrocytes [21] and cells with an osteoblastic phenotype from rat parietal bone [22]. We first did immunostaining of the rabbit knee tissue to know the regional difference in expression of TGF- $\beta$ level. Our results show that TGF- $\beta$ express in all different region of rabbit knee with regional variation in expression. The outer meniscus cells shows most staining and then gradually staining goes down toward inner meniscus and this may be the one of the reasons inner meniscus poorly heal when compare to outer meniscus. The articular cartilage shows the moderate level of TGF- $\beta$ expression when compare to meniscus tissue. Interesting results in rabbit meniscus made us curious to analyze level of TGF $\beta 1$ in human meniscus. Interestingly, $\operatorname{TGF} \beta 1$ expression in inner meniscus is lower than outer meniscus.

The next step was to assess the effect of recombinant TGF- $\beta 1$ on these different tissues of same rabbit knee joint. Our results indicate that outer, inner meniscus and articular cartilage chondrocytes when cultured in TGF- $\beta 1$ enriched medium displayed increased cell number compared to controls. In addition, the dose-dependent effect of TGF- $\beta 1$ on cell proliferation was found between the concentration ranges of $5-10 \mathrm{ng} / \mathrm{mL}$. This range is very important in the future therapeutic applications of the TGF- $\beta 1$ in cartilage healing. This is consistent with previous findings reported by other researcher $[5,23]$. We determine the regional differences in the cell proliferation response to TGF- $\beta 1$. The cell proliferation is higher in outer meniscal cells than inner and articular cartilage. This varying response between the tissues of same joints may be due to number of TGF $\beta$ receptors per cell. We did not observed any tremendous change in cell morphology in samples cultured with medium containing TGF- $\beta 1$. It is known that cells in culture have a tendency to change their phenotype and behavior especially in cell lines. Tissue handling is an important factor in securing cell viability and may also affect cell behavior [6]. In this study, the experiments were carried out on meniscus and articular cartilage cells from primary cultures that have been passage only twice to reduce their tendency to dedifferentiate.

To ascertain the effects of TGF- $\beta 1$, we examined the cell cycle regulatory effect of TGF- $\beta 1$ in rabbit meniscus and articular cartilage cells in vitro. We show that pretreatment with PD98059 significantly blocked the mitogenic and cell cycle promotive effects of TGF- $\beta 1$ (MTT assay). PD98059 is an inhibitor for MAP kinase kinases 1 and 2 (MKK), also called MAP/ERK kinases (MEK), the upstream activator of ERK1/2. These results suggest that phosphorylated ERK1 is necessary to maintain and promote cell cycle progression under TGF- $\beta 1$ stimulation. Our results agree with earlier reports showing that ERK1/2 plays a crucial mediating role in mitogenic signaling of TGF- $\beta 1$ in rat articular chondrocytes [24] and airway smooth muscle cell [25]. We used another small molecule inhibitor SB-431542 that potently inhibits TGF- $\beta$ RI activity at nanomolar concentrations $[16,17]$. Our data showed SB-431542 molecule counteract TGF$\beta 1$ mediated growth leading to cell inhibition on inner, outer and articular cartilage cell. There are also reports that SB-431542 inhibited TGF- $\beta 1$ mediated proliferation of osteosarcoma cell line that is growth stimulated in response to TGF- $\beta 1$ [26].

Chondrocytes and their extracellular matrix (ECM) are the two major components in cartilage biology, both playing critical roles in maintaining tissue integrity and function. We analysis the ECM genes and showed that the presence of type II collagen was enhanced in TGF- $\beta 1$ treated cultures in outer, inner and articular cartilage. Similar type of finding was reported in meniscus [27] and articular cartilage cell [28] when stimulated by TGF$\beta 1$ exogenous treatment or gene transfer. The inner meniscus showed more collagen type II than outer and articular cartilage. This may be due to anatomical variation in the tissue, it is well known that inner meniscus predominantly contain collagen type II and outer meniscus contain collagen type I [2]. Our data also showed that there is increase in proteoglycan synthesis such as aggrecan and biglycan in the presence of TGF- $\beta 1$. We also found regional variation in biglycan synthesis following TGF- $\beta 1$ stimulation. The inner meniscus showed significantly up-regulation of biglycan synthesis than outer and articular cartilage. There are reports that TGF- $\beta 1$ enhanced biglycan synthesis, and increased the length of the GAG chains on all secreted Proteoglycan [5,29] but little is known about the significance of biglycan up regulation following TGF- $\beta 1$ stimulation. There is no significant different in the regional variation of the aggrecan synthesis of knee joint after TGF- $\beta 1$ stimulation. To considering clinical application of our results, we should collect more histological and biomechanical data on knee tissues using the current approach in human and larger animal models.

The signal pathways activated by growth factors are complex. It will be interesting to analysis the regional variation in expression of other growth factors (IGF, FGF and platelet derived growth factor) and their receptors which play important roles in cell proliferation and ECM synthesis. In summary, these experiments highlight the regional variation in expression and stimulatory activity of TGF- $\beta 1$ in articular cartilage and meniscal fibrochondrocytes. This study also indicates that meniscus cells 
from the avascular zone (inner meniscus) of the meniscus are capable of responding favorably to the addition of TGF- $\beta 1$. Although this was an in vitro study, we made encouraging observations that can form the basis for in vivo research aimed at enhancing articular cartilage and meniscal repair, even within the avascular zone, following surgical repair. Such type of study has immense clinical significance because it will give important information about which region of organ is more benefited from particular growth factor that could potentially help to develop better and more effective treatment strategies.

\section{REFERENCES}

[1] P. Ghosh, Y. Numata, S. Smith, R. Read, S. Armstrong and K. Johnson, "The Metabolic Response of Articular Cartilage to Abnormal Mechanical Loading Induced by Medial or Lateral Meniscectomy," Agents and Actions Supplement, Vol. 39, 1993, pp. 89-93.

[2] J. Sanchez-Adams and K. Athanasiou, "The Knee Meniscus: A Complex Tissue of Diverse Cells," Cellular and Molecular Bioengineering, Vol. 2, No. 3, 2009, pp. 332340. http://dx.doi.org/10.1007/s12195-009-0066-6

[3] S. P. Arnoczky, "Building a Meniscus. Biologic Considerations," Clinical Orthopaedics and Related Research, No. 367, 1999, pp. S244-S253.

http://dx.doi.org/10.1097/00003086-199910001-00024

[4] M. Cucchiarini, S. Schetting, E. F. Terwilliger, D. Kohn and H. Madry, "rAAV-Mediated Overexpression of FGF2 Promotes Cell Proliferation, Survival, and Alpha-SMA Expression in Human Meniscal Lesions," Gene Therapy, Vol. 16, No. 11, 2009, pp. 1363-1372. http://dx.doi.org/10.1038/gt.2009.91

[5] S. Collier and P. Ghosh, "Effects of Transforming Growth Factor Beta on Proteoglycan Synthesis by Cell and Explant Cultures Derived from the Knee Joint Meniscus," Osteoarthritis and Cartilage, Vol. 3, No. 2, 1995, pp. 127-138. http://dx.doi.org/10.1016/S1063-4584(05)80045-7

[6] T. Tanaka, K. Fujii and Y. Kumagae, "Comparison of Biochemical Characteristics of Cultured Fibrochondrocytes Isolated from the Inner and Outer Regions of $\mathrm{Hu}-$ man Meniscus," Knee Surgery, Sports Traumatology, Arthroscopy, Vol. 7, No. 2, 1999, pp. 75-80. http://dx.doi.org/10.1007/s001670050125

[7] J. A. Buckwalter, H. J. Mankin and A. J. Grodzinsky, "Articular Cartilage and Osteoarthritis," Instructional Course Lectures, Vol. 54, 2005, pp. 465-480.

[8] M. W. Lark, E. K. Bayne, J. Flanagan, C. F. Harper, L. A. Hoerrner, N. I. Hutchinson, I. I. Singer, S. A. Donatelli, J. R. Weidner, H. R. Williams, R. A. Mumford and L. S. Lohmander, "Aggrecan Degradation in Human Cartilage. Evidence for Both Matrix Metalloproteinase and Aggrecanase Activity in Normal, Osteoarthritic, and Rheumatoid Joints," Journal of Clinical Investigation, Vol. 100, No. 1, 1997, pp. 93-106. http://dx.doi.org/10.1172/JCI119526

[9] L. A. Fortier, H. O. Mohammed, G. Lust and A. J. Nixon,
"Insulin-Like Growth Factor-I Enhances Cell-Based Repair of Articular Cartilage," Journal of Bone \& Joint Surgery, Vol. 84, No. 2, 2002, pp. 276-288. http://dx.doi.org/10.1302/0301-620X.84B2.11167

[10] S. B. Trippel, M. C. Whelan, M. Klagsbrun and S. R. Doctrow, "Interaction of Basic Fibroblast Growth Factor with Bovine Growth Plate Chondrocytes," Journal of Orthopaedic Research, Vol. 10, No. 5, 1992, pp. 638646. http://dx.doi.org/10.1002/jor.1100100506

[11] F. D. Shuler, H. I. Georgescu, C. Niyibizi, R. K. Studer, Z. Mi, B. Johnstone, R. D. Robbins and C. H. Evans, "Increased Matrix Synthesis Following Adenoviral Transfer of a Transforming Growth Factor Betal Gene into Articular Chondrocytes," Journal of Orthopaedic Research, Vol. 18, No. 4, 2000, pp. 585-592. http://dx.doi.org/10.1002/jor.1100180411

[12] E. N. Blaney Davidson, E. L. Vitters, P. M. van der Kraan and W. B. van den Berg, "Expression of Transforming Growth Factor-Beta (TGFbeta) and the TGF-Beta Signalling Molecule SMAD-2P in Spontaneous and InstabilityInduced Osteoarthritis: Role in Cartilage Degradation, Chondrogenesis and Osteophyte Formation," Annals of the Rheumatic Diseases, Vol. 65, No. 11, 2006, pp. 14141421. http://dx.doi.org/10.1136/ard.2005.045971

[13] H. L. Moses and R. Serra, "Regulation of Differentiation by TGF-Beta," Current Opinion in Genetics \& Development, Vol. 6, No. 5, 1996, pp. 581-586. http://dx.doi.org/10.1016/S0959-437X(96)80087-6

[14] P. A. Hoodless and J. L. Wrana, "Mechanism and Function of Signaling by the TGF Beta Superfamily," Current Topics in Microbiology and Immunology, Vol. 228, 1998, pp. 235-272.

http://dx.doi.org/10.1007/978-3-642-80481-6_10

[15] S. H. Tsai, M. T. Sheu, Y. C. Liang, H. T. Cheng, S. S. Fang and C. H. Chen, "TGF-Beta Inhibits IL-1beta-Activated PAR-2 Expression through Multiple Pathways in Human Primary Synovial Cells," Journal of Biomedical Science, Vol. 16, 2009, p. 97.

http://dx.doi.org/10.1186/1423-0127-16-97

[16] G. J. Inman, F. J. Nicolás, J. F. Callahan, J. D. Harling, L. M. Gaster, A. D. Reith, N. J. Laping and C. S. Hill, "SB-431542 Is a Potent and Specific Inhibitor of Transforming Growth Factor-Beta Superfamily Type I Activin Receptor-Like Kinase (ALK) Receptors ALK4, ALK5, and ALK7," Molecular Pharmacology, Vol. 62, No. 1, 2002, pp. 65-74. http://dx.doi.org/10.1124/mol.62.1.65

[17] N. J. Laping, E. Grygielko, A. Mathur, S. Butter, J. Bomberger, C. Tweed, W. Martin, J. Fornwald, R. Lehr, J. Harling, L. Gaster, J. F. Callahan and B. A. Olson, "Inhibition of Transforming Growth Factor (TGF)-Beta1-Induced Extracellular Matrix with a Novel Inhibitor of the TGF-Beta Type I Receptor Kinase Activity: SB-431542," Molecular Pharmacology, Vol. 62, No. 1, 2002, pp. 5864. http://dx.doi.org/10.1124/mol.62.1.58

[18] L. Longobardi, L. O'Rear, S. Aakula, B. Johnstone, K. Shimer, A. Chytil, W. A. Horton, H. L. Moses and A. Spagnoli, "Effect of IGF-I in the Chondrogenesis of Bone Marrow Mesenchymal Stem Cells in the Presence or Absence of TGF-Beta Signaling," Journal of Bone and Mineral Research, Vol. 21, No. 4, 2006, pp. 626-636. 
http://dx.doi.org/10.1359/jbmr.051213

[19] T. Tsukazaki, T. Usa, T. Matsumoto, H. Enomoto, A. Ohtsuru, H. Namba, K. Iwasaki and S. Yamashita, "Effect of Transforming Growth Factor-Beta on the Insulin-Like Growth Factor-I Autocrine/Paracrine Axis in Cultured Rat Articular Chondrocytes," Experimental Cell Research, Vol. 215, No. 1, 1994, pp. 9-16. http://dx.doi.org/10.1006/excr.1994.1307

[20] K. T. Rousche, B. C. Ford, C. A. Praul and R. M. Leach, "The Use of Growth Factors in the Proliferation of Avian Articular Chondrocytes in a Serum-Free Culture System," Connective Tissue Research, Vol. 42, No. 3, 2001, pp. 165174. http://dx.doi.org/10.3109/03008200109005647

[21] J. D. Richmon, A. B. Sage, V. W. Wong, A. C. Chen, C. Pan, R. L. Sah and D. Watson, "Tensile Biomechanical Properties of Human Nasal Septal Cartilage," American Journal of Rhinology, Vol. 19, No. 6, 2005, pp. 617-622.

[22] M. Centrella, T. L. McCarthy and E. Canalis, "Transforming Growth Factor Beta Is a Bifunctional Regulator of Replication and Collagen Synthesis in Osteoblast-Enriched Cell Cultures from Fetal Rat Bone," Journal of Biological Chemistry, Vol. 262, No. 6, 1987, pp. 28692874.

[23] M. K. Akens and M. B. Hurtig, "Influence of Species and Anatomical Location on Chondrocyte Expansion," BMC Musculoskeletal Disorders, Vol. 6, 2005, p. 23. http://dx.doi.org/10.1186/1471-2474-6-23

[24] A. Yonekura, M. Osaki, Y. Hirota, T. Tsukazaki, Y. Miyazaki, T. Matsumoto, A. Ohtsuru, H. Namba, H. Shindo and S. Yamashita, "Transforming Growth Factor-Beta Stimulates Articular Chondrocyte Cell Growth through p44/42 MAP Kinase (ERK) Activation," Endocrine Journal, Vol. 46, No. 4, 1999, pp. 545-553.

http://dx.doi.org/10.1507/endocri.46.545

[25] G. Chen and N. Khalil, "TGF-Beta1 Increases Proliferation of Airway Smooth Muscle Cells by Phosphorylation of Map Kinases," Respiratory Research, Vol. 7, 2006, p. 2. http://dx.doi.org/10.1186/1465-9921-7-2

[26] S. Matsuyama, M. Iwadate, M. Kondo, M. Saitoh, A. Hanyu, K. Shimizu, H. Aburatani, H. K. Mishima, T. Imamura, K. Miyazono and K. Miyazawa, "SB-431542 and Gleevec Inhibit Transforming Growth Factor-BetaInduced Proliferation of Human Osteosarcoma Cells," Cancer Research, Vol. 63, No. 22, 2003, pp. 7791-7798.

[27] H. Goto, F. D. Shuler, C. Niyibizi, F. H. Fu, P. D. Robbins and C. H. Evans, "Gene Therapy for Meniscal Injury: Enhanced Synthesis of Proteoglycan and Collagen by Meniscal Cells Transduced with a TGFbeta(1)Gene," Osteoarthritis and Cartilage, Vol. 8, No. 4, 2000, pp. 266271. http://dx.doi.org/10.1053/joca.1999.0300

[28] P. Galéra, D. Vivien, S. Pronost, J. Bonaventure, F. Rédini, G. Loyau and J. P. Pujol, "Transforming Growth Factor-Beta 1 (TGF-Beta 1) Up-Regulation of Collagen Type II in Primary Cultures of Rabbit Articular Chondrocytes (RAC) Involves Increased mRNA Levels without Affecting mRNA Stability and Procollagen Processing," Journal of Cellular Physiology, Vol. 153, No. 3, 1992, pp. 596-606. http://dx.doi.org/10.1002/jcp.1041530322

[29] K. G. Vogel and D. J. Hernandez, "The Effects of Transforming Growth Factor-Beta and Serum on Proteoglycan Synthesis by Tendon Fibrocartilage," European Journal of Cell Biology, Vol. 59, No. 2, 1992, pp. 304-313. 